\title{
Violência e risco de suicídio na contrução das masculinidades adolescentes*
}

\author{
Welson Barbosa Santos** \\ Nilson Fernandes Dinis***
}

\section{Resumo}

Esta discussão sustenta-se na definição de que existem diversas masculinidades submetidas a uma trama de discursos, de saberes $e$ de relações de poder. São mecanismos que impõem verdades assujeitadoras e desencadeiam processos de objetivação $e$ subjetivação, podendo desencadear violência e suicídio. $\mathrm{O}$ objetivo do trabalho é discutir, a partir dos processos de objetivação e subjetivação, suas implicações em relação à construção da masculinidade entre adolescentes. Os dados foram edificados a partir de entrevistas realizadas com 17 estudantes de duas escolas de ensinos fundamental e médio, e o uso do espaço virtual, por via de entrevistas semiestruturadas, possibilitou acessar e observar falas. A metodologia empregada sustenta-se no conceito de discurso de Michel Foucault e os recortes das falas dos sujeitos subsidiaram sinalizar a forma como discursos incidem sobre o masculino adolescente.

Palavras-chave: Gênero, Sexualidade, Adolescência, Masculinidade, Discurso, Suicídio.

\footnotetext{
* Recebido em 13 de julho de 2015, aceito em 02 de fevereiro de 2017. Este artigo é resultado de uma pesquisa vinculada ao Programa de Pós-graduação PPGE da Universidade Federal de São Carlos - UFSCar. O projeto teve apoio e financiamento da CAPES, tendo sido indicado ao Prêmio CAPES em 2016.

** Professor Adjunto da Universidade Federal de Goiás, Goiânia, GO, Brasil. wwsantosw@yahoo.com.br

*** Professor adjunto do Programa de Pós-Graduação em Educação da Universidade Federal de São Carlos (UFSCar), São Carlos, SP, Brasil. ndinis@ufscar.br 


\title{
Violence and Suicide Risk in The Construction of Teenage Masculinities
}

\begin{abstract}
This discussion focus on the concept that there are different masculinities and, once submitted to a web of discourses, knowledge and power relationships, such processes impose subjugated truths, triggering objectification, subjectivation and can induce violence and suicide. Thus, this paper aims at discussing, from the mechanisms of objectivation and subjectivation, their implications regarding the building of masculinity amongst teenagers. The data was built from interviews done with 17 students from two Secondary and High Schools and the use of cyber space, guided by semi-structured interviews, allowed us to access and observe those speeches. The methodology used is founded on Michel Foucault's concept of discourse and the selection of the subjects' speeches allowed us to signal how discourses influence male teenagers.
\end{abstract}

Keywords: Gender, Sexuality, Adolescence, Masculinity, Discourse, Suicide. 


\section{Introdução}

Este artigo tem como objetivo identificar os processos de objetivação e subjetivação e discutir as implicações desses processos em relação ao processo de construção das masculinidades entre adolescentes, além de contribuir para discussões no campo do que se entende de adolescência ${ }^{1} e$ masculinidade, a partir dos conceitos dados por Ariès (1981) e Peralva (1997). A proposta é perceber as práticas e os discursos instituídos e sustentados pela norma - heteronormatividade $e^{2}-e$ que incidem sobre os adolescentes. Nesse percurso, será possível perceber que há casos em que as relações de poder deixam de ser produtivas, como descreve Foucault (2007), propiciando situações de violência e risco de suicídio entre adolescentes do sexo masculino.

Assim, na busca por melhor estruturar o debate proposto, inicialmente o caminho assumido será o de fortalecer saberes que subsidiam o entendimento de que a adolescência é invenção humana, um registro discursivo em que

\footnotetext{
1 Tomando a base sociopolítica dessa diferenciação, supõe-se que o termo adolescência tenha surgido simultaneamente às transformações nas estruturas sociais ocorridas ao final do século XIX. Foi nos séculos VI e VII que se deu maior ênfase para divisões de fases etárias de mulheres e homens. Percebe-se que citar o termo adolescência somente foi possível no interior de determinada configuração de saberes, os quais possibilitaram apreensões do "homem" como objeto de investigações empíricas.

2 Criado por Michael Warner e descrito em seu trabalho intitulado Fear of a queer planet, publicado em 1991, o vocábulo "heteronormatividade" refere-se ao padrão da heterossexualidade que toma lugar de normal e única, sendo as demais formas de sexualidade tidas como subalternas, clandestinas, ilegais ou anormais. O termo deriva do grego hetero, diferente, e norma, esquadro, e possui raízes nos princípios de Gayle Rubin do sistema sexo/gênero discutido no artigo "O tráfico de mulheres" (1975). É usado para exploração e crítica de normas tradicionais de sexo, identidade de gênero, papel social de gênero $e$ sexualidade e implicações sociais de tais instituições. Descritivo, categoriza e vincula comportamento social $e$ autoidentidade com os tipos de genitália.
} 
O adolescente é concebido como objeto de um discurso científico capaz de compreendê-lo em suas determinações essenciais, para então propor alternativas terapêuticas capazes de abordar e sanar os problemas dessa época peculiar em que os jovens "adoecem" como que naturalmente (César, 1998:31).

Nesse sentido, estudiosas/os desafiadas/os a fazer uma leitura crítica da adolescência são unânimes em reconhecer que a proximidade dos discursos psicológico, médico e pedagógico, responsabilizou-se pela edificação e sustentação da visão universal, essencialista e a-histórica, da adolescência. Jobim e Souza (1998), Coimbra, Bocco e Nascimento (2005), Ozzela (2002), César (1998), Castro (1999; 2001), dentre outros/as, ao discutirem esse tema, contextualizam historicamente essa construção e, por um viés sociológico, oferecem subsídios para desnaturalizações e melhor compreensão.

Ademais, o debate sobre naturalização de discursos encontra respaldo no pensamento de Foucault (1979), o qual afirma que os discursos de naturalização são dispositivos que tratam da história não centrada em sujeitos históricos, mas em práticas institucionais e políticas que constituem os sujeitos.

Objetivamente o termo dispositivo tenta demarcar

[...] um conjunto decididamente heterogêneo que engloba discursos, instituições, organizações arquitetônicas, decisões regulamentares, leis, medidas administrativas, enunciados científicos, proposições filosóficas, morais e filantrópicas (Foucault, 1979:244).

Pela descrição, o dito e o não dito são elementos do discurso. Assim, é importante observar que, entre os elementos discursivos, existe um tipo de jogo, de mudanças de posição e de modificações de funções, sendo importantes por possibilitarem uma observação atenta ao momento em que práticas e discursos históricos transformaram-se em objetos naturais e orientaram ao que se denominou de adolescência. 
Trata-se de processos de naturalização que viabilizam perceber as condições específicas em que ocorre produção dos discursos e como são e foram constituídos nesse campo de saber. Eles enquadram transformações e adequações vividas na forma adolescente, comuns para todos/as, reforçando sua existência equivalente ao mesmo objeto tratado na Grécia, Roma antiga, Idade Média Cristã e séculos XIX, XX e XXI. Portanto, ao longo deste trabalho, ao mencionar o termo adolescência, ele deve ser reconhecido como uma forma edificada pelo discurso, cujo objetivo é não reconhecê-la como se algo natural.

Sobre a construção das masculinidades adolescentes, pressupomos que as subjetividades e os processos de objetivação ${ }^{3}$ nesse campo, como Foucault (1995) possibilita afirmar, estão submetidos aos mesmos dispositivos, quer se esteja na escola, no convívio familiar, assim como nos demais espaços sociais de interação. Essa percepção auxilia a entender a força $e$ a potencialidade da norma, pois são regras e procedimentos de alteração e moldagem, identificadas na psicologia, na educação $e$ na medicina higienista, voltadas para objetivar cada um/a. Pelo descrito, não se trata de uma relação do/a adolescente consigo mesmo/a na ótica da interioridade, mas do governo de si e assim ocorre a subjetivação. Sobre tal discussão, Foucault (2011b:87) descreve bem a temática a partir de um conhecido texto grego de Cícero nas Tusculanas.

Desde que nascemos e somos admitidos em nossas famílias, encontramo-nos em um meio inteiramente falseado, onde a perversão dos julgamentos é completa,

3 Sobre subjetivação, trata-se de reforços nas constituições de sujeitos $e$ mecanismos de poder e de vontade de verdade que atravessa cada um/a. É a ética enquanto constituição de si, como sujeito para si mesmo e de seus próprios atos. Ética que passa por tal vontade de verdade. Seria saber de si para si em uma procura de verdades centralizadas. $\mathrm{O}$ autor ainda viabiliza afirmar que a subjetivação refere-se ao processo constitutivo de cada um/a e, como mecanismo, possibilita objetivação. A seu turno, seria então, o conceito, o preconceito, aquilo que é descritivo de alguém, a partir do referencial dado por quem vê e observa. 
tanto que pode se dizer, sugamos o erro como leite de nossas amas. Crítica, pois, da primeira infância e das condições em que ela se desenrola. Crítica também do meio familiar, não somente de seus efeitos educativos, como ainda, se quisermos (pelo) conjunto de valores que ele transmite ou impõe; crítica do que, em nosso vocabulário, chamaríamos de ideologia familiar. Penso naquela carta de Sêneca a Lucílio, em que diz: Põe-te em segurança, tenta reencontrar a ti mesmo, bem sei que teus pais almejaram para ti coisas bem diferentes.

Nesse raciocínio, procedem também de Foucault (2003) reflexões sobre o poder como integrante de relações humanas no cotidiano. No tocante às relações de poder, o autor descreve a forma das relações atuarem no corpo que vão propiciando materializações - consequência dos elementos que chegam até ele.

Inicialmente, vale afirmar que os modos de objetivação produzem sujeitos singulares, consequência de discursos uma vez mobilizados. Isso demanda discussões de tecnologias do eu como forma de subjetividade moderna, a qual produz, sob uma injunção geral do poder-saber, a verdade da pessoa, sendo movimento que retira das profundezas do inconsciente de cada um/a suas verdades. São aparatos voltados para que todos/as continuem sendo produzidas/os e reproduzidas/os por meio dos dispositivos da sexualidade, de acordo com Foucault (2007). Referente à "Scientia sexualis", Carrara $(2015 ;$ 2016) identifica que tais mecanismos continuam ativos e amplamente empregados. Após as descrições feitas atinentes ao discurso, com o propósito de estruturar o tema com clareza e entendimento, foram traçados caminhos metodológicos que nos permitiram ouvir adolescentes do sexo masculino e observar seus discursos.

\section{Metodologia}

Com base no fundamento que masculinidades têm sido edificadas nas relações socioculturais e em espaços como a escola 
e a internet (Miskolci, 2011), este trabalho, para articular as duas esferas, envolveu inicialmente 600 sujeitos de duas instituições de ensino. Desse total, $200^{4}$ deles, do sexo masculino e com idade entre 14 a 16 anos, foram convidados a participar da segunda etapa da pesquisa. Destes, 135 aceitaram o convite, responderam a um questionário objetivo $e$, a partir das respostas obtidas, foi possivel a seleção de 17 participantes finais.

Os questionários usados nas duas etapas foram elaborados a partir das orientações dadas por Mann e Stewart (2000). O uso de rede social virtual foi referenciado nas considerações de Marcuschi (2004), Freitas et al. (2004) e Miskolci (2011). Nas entrevistas realizadas - terceira etapa -, propôs-se uma discussão sobre o tema "conflitos masculinos na adolescência". De acordo com as respostas, abriam-se caminhos para perguntas específicas feitas ao grupo, muito além do pré-estabelecido, questões que abordavam assuntos como família, religião, entre outros. As perguntas reaplicadas aos participantes, em ordem aleatória, foram:

- Como é, para você, sentir-se discriminado ou perceber algum tipo mais frequente de cobrança ao interagir entre os colegas?

- Os colegas cobram de você ser mais masculino?

- Devido a observações e conclusões aparentes, já foi taxado de gay, viado ou homossexual?

- Pré-julgamentos sobre sua identidade sexual já lhe fizeram sentir-se excluído de grupos na escola?

\footnotetext{
4 O questionário objetivo, com opção de respostas "sim" ou "não", respondido pelos 135 alunos, foi disponiblizado aos participantes em uma sessão de acesso restrito da página virtual de relacionamento - www.facebook.com. A sessão chama-se grupos. As respostas possiblitaram acessar o total de 17 sujeitos, identificados por responderem "sim" a todas as perguntas feitas referentes a terem vivenciado situações de questionamento e contrangimento na escola sobre suas masculinidades.
} 
Encorajar e orientar a participação dos entrevistados $e$ procurar a adaptação às falas, tendo como referência as orientações de Miskolci (2011), possibilitou discutir temas ligados a família, religião, escola e dinâmicas discursivas que cada um experimenta no cotidiano sobre sexualidade e gênero. Ainda, ao executar entrevistas online, as falas foram colhidas orientadas por um roteiro prévio, com ciência de o ambiente ter suas formas de coerção e de estresse. Também, obedecendo aos critérios éticos de uma pesquisa científica, foram solicitadas autorizações das escolas onde o trabalho foi realizado, procedendo-se, do mesmo modo, em relação aos pais e/ou responsáveis dos entrevistados que aceitaram voluntariamente participar das entrevistas.

O material produzido contribuiu para o entendimento dos componentes $e$ processos sociais de constituição das masculinidades adolescentes ocorrida na escola e demais espaços ocupados por tais sujeitos e seus correlatos. Ademais, por ser recurso metodológico que possibilitou analisar as falas dos entrevistados, buscaremos ainda fortalecer o conceito de discurso, como ele ocorre e sua funcionalidade (Foucault, 2010; 2011a).

Ao observar o discurso, Ficher (2001) orienta, é preciso recusar explicações unívocas, fáceis e a busca insistente do sentido último e oculto das coisas, pois essa é prática bastante comum $e$ incorreta. Portanto, usando-se do discurso, é preciso ficar no nível de existência das palavras e coisas ditas e isso equivale a trabalhar arduamente, deixando que o discurso mostre-se na sua complexidade peculiar (Fernandes, 2012).

No entanto, para Fischer (2001), alcançar tal empreito exige desprender-se de longo e eficaz aprendizado que gera olhar o discurso apenas como um conjunto de signos e/ou significantes que se referem a determinados conteúdos, carregando tal ou qual significado, quase sempre oculto, dissimulado, distorcido, intencionalmente deturpado, cheio de reais intenções, conteúdos e representações escondidas em textos e pelos textos, e não logo visíveis. Fernandes (2012) corrobora afirmando que é como se no interior do discurso, ou em tempos anteriores a ele, fosse possível encontrar verdades intocadas. Assim, é importante perceber que 
nada há por trás das cortinas do discurso, nem sob o chão que se pisa; o que existem são enunciados e relações que o próprio discurso põe em funcionamento (Foucault, 2008). Então, ao usar recortes de fala de adolescentes sobre construções de suas masculinidades, aspirou-se verificar o discurso presente nesses comentários e as relações históricas e práticas da questão e seu envolvimento com a subjetivação e a objetivaçao.

\section{Discussão}

O trabalho aqui apresentado sustenta-se no conceito de que existem diversas masculinidades, como afirmam Connell (1995) e Badinter (1999), temática mais amplamente discutida por Connell e Messerschmidt (2013). Para as autoras e o autor, trata-se da consequência das próprias necessidades e subjetividades de cada um, e, para identificá-las, basta observar embates sociais vivenciados e descritos nos fragmentos de fala aqui presentes. Com considerações que encontram respaldo nos trabalhos de Santos (2015), Santos e Dinis (2013), Parker (1997) e Connell e Messerschmidt (2013), os recortes apresentados pressupõem que entre adolescentes a homossexualidade é usada para o fortalecimento da heterossexualidade normativa, na medida em que acusa, sinaliza e condena masculinidades não hegemônicas.

No que tange ao processo de subalternização das homossexualidades, segundo Parker (1997) e Fry (1982), há valorização do homossexual que assume um papel ativo na relação sexual entre homens, em detrimento do demérito ao que a postura é passiva. Nesse contexto, percebemos que há um embate centrado no "ser para os/as outros/as" e no "tentar negar-se", no "esconder-se", inclusive, por trás de identidades heterossexuais (Miskolci, 2006). O fragmento abaixo parece-nos exemplificar isso.

Nas relações homossexuais sempre fui o ativo da relação $e$ transava iludido por uma "amizade verdadeira". Esse era o argumento usado quando reagia contra o ficar junto para transar. Minha experiência nessa área foi só com um homem. Sentia ereção, ejaculava, mas sou homem. Eu 
entendo que eu era muito sozinho na infância, por isso achava que aquilo que vivia com o cara me levaria a uma amizade verdadeira, mas a meu ver eu nunca tive o amigo que sonhava, mesmo transando (Sujeito 9).

O fragmento confirma as exposições de Parker (1998) e Fry (1982), além de propiciar discussões de que construções da masculinidade são desafio complexo, inacabado e que o não alcance pleno do padrão hegemônico, como discute Connell $e$ Messerschmidt (2013), sinaliza motivos de desajuste e conflito sobre o conceito de si mesmo, ou seja, de sua subjetividade. E, uma vez fora da norma, como o recorte mostra, há prazer e ao mesmo tempo busca por reconhecimento ao ajuste.

Vejo todo o meu envolvimento com alguém do mesmo sexo como atraso na minha vida. Tenho medo que isso venha comprometer-me como homem. Me relacionar com alguém do mesmo sexo sem vontade, mesmo tendo ereção e fazendo sexo oral, aquilo me deixava com tanto ódio depois. Mas eu não reagia, só pensava. Mas não acho que tem a ver, porque me sinto homem, sou macho e não concordo que eu seja gay. As pessoas não desconfiam disso, para elas sou hétero; então eu sou (Sujeito 9).

O comentário de fala pode servir como sinalização do campo de forças subjetivadoras que incidem sobre o adolescente $e$, embora viva dilemas e negação verbal sobre suas vivências homossexuais, acomoda-se pelos modos de objetivação que o envolvem. Ao afirmar que faz sexo com alguém do mesmo sexo, ocorrendo ereção e sexo oral, há aí uma subjetividade, contudo, sente-se homem, macho, não concorda em ser gay, ou seja, acomoda-se em processos de objetivação e ao confortável campo normativo que o reconhece como heterossexual.

Nessa linha de raciocínio, existem padrões esperados $e$ diferentes estéticas masculinas, tidas como fora da norma e de fácil percepção, por despertarem objetivação diferente do esperado e estabelecido. Entendido isso, para ampliar a discussão, 
serão usadas como referência as problematizações gregas sobre o masculino. Para Foucault (2011b), trata-se de um campo moral particular, implicado em técnicas de si e que tinha o objetivo de atingir a estética da existência $e$ a forma ideal de autocondução no mundo, sendo regras de temperança que deveriam ser seguidas $e$ praticadas. Eram orientações centradas no exercício do poder sobre si e na prática da liberdade e constituíam-se de regras voltadas para a condução de cada um, produzindo subjetividades $e$ sendo discursos carregados de preceitos de moral. Nesse caminho, o que podemos observar é que a prática subsistiu, foi ajustada e é facilmente identificada no processo de subjetivação de adolescentes, ilustrado pelos recortes de fala que pressupõem isso.

Em relação à moral investida na conduta sexual entre os gregos, Foucault (2010; 2011b) destaca que se centrava no bom uso dos prazeres e no estilo temperante de viver e cuidar do corpo, da saúde, da casa e de prazeres com rapazes. Para tornarse sujeito de atos morais, exigia-se comportamento austero, mesmo que fosse necessária a renúncia de prazeres. Portanto, observa-se que o castigo e a punição estavam ausentes. Na era cristã, a moral tornou-se rígida, unificada, coerente e autoritária $e$ no lugar do prazer apareceu a carne como fruto proibido. Foucault (2007) confirma que, para tornar-se sujeito de seus atos, foi preciso que ocorresse uma submissão aos princípios universais, como o libertar-se da carne e do desejo.

Pelo já descrito, iniciou-se aí uma hermenêutica do sujeito, do desejo e que precisava de uma decifração de verdade por meio da confissão e das purificações da carne e, por consequência, do autoexame. Sabe-se que alguns desses comportamentos chegaram até nós e têm na psicanálise a forma privilegiada de conhecimento do desejo, porque busca a origem, o desenvolvimento $e$ a decifração dele. Respaldados em Foucault (2011b), entendemos que o adolescente masculino acaba impondo sua marca à prescrição, representada pelo dominar-se, provar-se ou transformar-se para atender às normas. Nesse sentido, o 
fragmento a seguir reforça o quanto esse adolescente tem que se moldar às normas.

Queria dar conta de discutir questões que leio sem me importar com quem tá (sic) ouvindo. Em relação a roupas, não vestiria muito diferente. Mas as blusas que eu já comprei de marca só fiz isso para fazer graça para os outros. Exemplo é que os tênis que eu gosto, eu não compro. Com as meninas, já fiquei por pressão, já beijei por pressão. Eu fico com raiva de mim mesmo por não conseguir ser o que eu acho que deveria, de não saber ao certo porque me importo tanto com que os outros irão pensar (Sujeito 4).

O recorte de fala pressupõe haver um campo de forças em que objetivações e subjetivações ocorrem $e$ atuam no sujeito em construção. São processos contínuos sobre cada um, que os atravessa e molda, agindo até sobre seus próprios ossos e músculos, sendo proporcional ao discurso que o alcança (Fernandes, 2012). Nessa perspectiva, fica entendido que há padrões esperados de masculinidade e há diferentes estéticas. Quanto ao sujeito em seu processo de subjetivação, ele está num campo de forças, em que a objetivação exercida sobre ele/a pode enquadrá-lo/a como sendo diferente do esperado ou não. $\mathrm{O}$ fragmento seguinte vem contribuir para tal afirmativa.

Quando penso no julgamento dos outros, tenho medo dos resultados desses julgamentos, de serem negativos e eu não ser como fui julgado $e$ isso me levar a ser excluído das brincadeiras e do grupo que sai junto e que é popular. Aí, saio, faço zoação, beijo, transo, embora não seja com quem quero. Faço tudo isso para não ser taxado de gay (Sujeito 4).

Afirmativas como: o julgamento do outro, o medo dos resultados desses julgamentos, ser diferente daquilo que podem achar que sou, ser excluído do grupo, deixar de fazer parte dos populares, podem pressupor que existam campos de forças nos 
quais ocorram tanto objetivação quanto subjetivação, $e$, ao mesmo tempo, são afirmações que mostram potencialidades tanto de poder quanto de resistir, existentes nesse campo. Daí, fazer e falar o que se espera é uma consequência e nisso se percebe a ética e a estruturação de modalidades de relação consigo e que permitem aos indivíduos constituírem-se como sujeitos de comportamento moral. Então, nesse campo de forças, possivelmente, adolescentes não se tornam sujeitos de seus atos, regidos pelas regras universais heteronormativas dimensionadas pelo seu falar.

Retomando os conceitos gregos, Foucault (2011b) diz que o termo afrodisia é o que melhor referencia o prazer do amor, relações sexuais e condutas voluptuosas na Grécia antiga. E, para o autor, o termo não corresponde nem ao conceito de carne nem de sexualidade, por serem criações discursivas posteriores aos conceitos dados pelos gregos que prezavam o amor pelo belo. Poderia ser o belo rapaz ou bela mulher, sendo contexto em que escolher era opção que cada um fazia. Também não se classificava o amor em tipos aceitáveis ou condenáveis, não o patologizavam ou o tratavam como objeto de grande preocupação moral, mas revestiam-no de valores, conselhos e exigências claras. Nos prazeres, no amor ao seu próprio sexo ou ao sexo oposto, é possível perceber que não faziam disso questões, como duas relações excludentes ou tipos de comportamento diferentes. $\mathrm{Na}$ Grécia, costumes frouxos eram o não saber resistir nem às mulheres nem aos rapazes, indistintamente.

É claro que a preferência pelos rapazes e pelas moças era facilmente reconhecida como um traço de caráter: os homens podiam se distinguir pelo prazer ao qual eram mais ligados; questão de gosto, que podia prestar-se a gracejos, mas não questão de tipologia implicando a própria natureza do indivíduo, a verdade de seu desejo ou a legitimidade natural de sua inclinação. Não se concebia dois apetites distintos, distribuindo-se em indivíduos diferentes; ou confrontando-se em uma mesma alma; encarava-se antes como duas maneiras de obter seu prazer, uma das quais 
convinha melhor a certos indivíduos ou a certos momentos da existência (Foucault, 2010:240-241).

Nota-se que na moral grega não havia códigos qualificando atos sexuais, o que existia era a ótica das posições sociais dos parceiros havendo benefícios e não desperdícios. A preocupação moral estava centrada na ética do domínio, do não desperdício, da relação entre a posição social do parceiro e daquele que sonha. Tratava-se de questões elaboradas concomitantemente com uma estética da existência, valendo mais o arcabouço jurídico das relações do que as classificações do normal e contrário à natureza, consideradas proibidas ou ruins em si mesmas.

Conforme Araújo (2000), mesmo na cultura greco-latina, se valorizava a atenção médica ao corpo, entrando aí as questões sexuais, porém inexistiam divisões de normal e anormal ou de desvios. Isso só ocorreu no fim do século II e, para Foucault (2007), tempo em que se iniciou a longa história das proibições, medo do castigo e negação ao sexo como condição para vida moral. Objetivamente, a afrodisia grega passou da moral da carne e da concupiscência para a condição de essencialmente má; e práticas do sexo tornaram-se pecado.

Portanto, buscar entender o amor grego entre o efebo e seu mestre e a percepção de relação entre pessoas do mesmo sexo, ao primeiro olhar parecem extremamente distantes. Na Grécia, o efebo era envolvido por ações voltadas para sua formação $e$ construção, cabendo ao adulto do mesmo sexo o compromisso estruturante e norteador. Em contrapartida, atualmente, esses são enfrentamentos conflitantes, mas possíveis de serem percebidos, exemplificados nos fragmentos de fala a seguir.

Em relação à minha crise, ela está nos meus pensamentos incontroláveis, na minha tentativa de controlá-los. Eu fico pensando que não posso virar gay e decepcionar todo mundo. E aí espontaneamente meu cérebro já responde: mas e se eu for? Nessa luta, me pego criando imagens $e$ nessa hora quando mais eu tento parar de pensar mais pensamentos homossexuais eu tenho (Sujeito 1). 
No meu caso, penso demais e perco o sono. Na última vez, foi de não aguentar mais, aí pensei até em procurar um psicólogo (Sujeito 4).

Quando me vi gostando de um colega de escola isso era ruim, eu não queria ser gay. Já tive pressão pra ficar com meninas pra provar minha heterossexualidade $e$ isso me chateou muito (Sujeito 3).

As afirmativas "não posso virar gay e decepcionar todo mundo, quando mais eu tento parar de pensar mais pensamentos homossexuais eu tenho, eu não queria ser gay", ou mesmo o seguinte fragmento,

queria ter família normal, queria mulher, filhos, queria ser o que a sociedade classifica como normal e já tive pressão pra ficar com meninas pra provar minha heterossexualidade (Sujeito 7)

Os recortes evidenciam como os mecanismos disciplinares, descritos por Carrara $(2015 ; 2016)$, com seus tentáculos, estão enraizados na sociedade e impõem sua marca de subjetivação nos sujeitos. No entanto, retomando a Grécia, o amor entre iguais era entendido como possibilidade e tais práticas não definiam o masculino e sua aceitabilidade ou não como futuro adulto (Foucault, 2010; 2011b). Os comentários inseridos até aqui sinalizam a importância de se observar o rechaço social somente pela não adequação de condutas, vestimentas, comportamentos e gestos, tidos como inadequados aos padrões da norma masculina. $\mathrm{O}$ recorte de comentário a seguir é mais um exemplo nesse campo de percepções.

Eu sei que não deveria me preocupar e todo dia me digo isso, mas acabo fazendo tudo de novo; é uma busca constante pelo que eu nunca vou ser e isso me maltrata, pois eu sei que ser o que eu sou é mais correto. Embora saiba também que ser assim me traz outras crises devido às 
zoações. Elas certamente me fazem sofrer também. Eu sei que essas zoações são pela roupa que posso vestir, pelo jeito que posso estar falando ou pela forma que ando (Sujeito 4).

$O$ recorte coloca questões e viabiliza refletir sobre o enquadramento esperado e a norma, investimento para a perpetuação de tais práticas, consoante Carrara (2015). São forças moldadoras exercidas sobre o sujeito, por vezes contraditórias, forçando novas estéticas ou ajustes. Do mesmo modo, comportamentos e práticas homossexuais, que foram e ainda são classificadas como vício próprio da delinquência juvenil (César, 1998), exigem reavaliações. São verdades produzidas e que se modificam no momento em que regras sofrem mudanças e, para entendê-las, basta pensar que em todos os tempos da história humana houve uma ética dissuadida em relação a cada um/a, ética de essência coletiva que se transforma e que perpassou os tempos.

Foucault (2004) afirma que essas questões podem ser identificadas na era moderna e diferenciadas por uma ética geral, manifestada na linguagem ao implicar a materialização de diferentes discursos sobre o tema, e confirmada nas considerações de Carrara (2015; 2016). Nesse caminho, referenciado em Fernandes (2012), é possível perceber que, em relação aos/as adolescentes, a linguagem visa a promover e/ou modificar subjetividades para inseri-los/as em espaços sociodiscursivos em que serão objetivados/as como singulares, inscritos/as em lugares de verdade e portadores/as de determinadas identidades. Há uma objetivação do indivíduo paralela ao que é feito com o sujeito.

A normatização funciona penalizando as mais leves faltas, graduando cada uma em relação aos demais, prevendo punição aos deslizes, articulando suas verdades com o ser individual. O objetivo é a diferenciação, a possibilidade de olhar do exterior o que é diferente dos demais. Nesse sentido, a criança $e$ não $o$ adulto, o doente $e$ não $o$ 
saudável, o criminoso e não o legalista e obediente constituem seu alvo predileto (Araújo, 2000:161).

Em conformidade com o discutido, assim funciona o poder da norma: diante do poder jurídico, há culpado ou inocente e, diante do poder da norma, o/a adolescente normal ou anormal.

É deste jogo que se constitui, lentamente desde há vários séculos, um saber do sujeito; saber não tanto de sua alma, mas daquilo que o cinde, daquilo que o determina talvez, mas sobretudo fazê-lo escapar de si mesmo. Isto pode parecer imprevisto, mas não deve absolutamente causar espanto quando se pensa na longa história da confissão cristã e judiciária, nos deslocamentos e transformações desta forma de saber-poder, tão capital no ocidente, que é a confissão: de acordo com círculos cada vez mais fechados, o projeto de uma ciência do sujeito pôs-se a gravitar em torno da questão do sexo. A causalidade no sujeito, o inconsciente do sujeito, a verdade do sujeito no outro que sabe, o saber nele no que ele próprio não sabe, tudo isso acabou por si desdobrar no discurso do sexo, não absolutamente, entretanto, em razão de alguma propriedade inerente ao sexo mesmo, mas em função das táticas de poder que são imanentes a esse discurso (Araújo, 2000:93-94).

A partir desse raciocínio, os gregos e seu pensar são auxiliadores, uma vez que entre eles não houve uma moral frouxa ou mesmo ausência de preocupação moral. No conceito de Araujo (2000), somados aos fragmentos aqui inseridos e ao que é entendido como adolescência, é possível perceber que nós, indivíduos modernos, somos em parte essa subjetividade confessante, incapazes de ver que esse modo de tratar e de discutir adolescência e correlatos como item urgente é apenas uma das voltas da história inventada por nós e para nós. Trata-se de identidade reconhecível, cognoscível, veraz, satisfatória que inventamos. 
Portanto, como Foucault (2007) sinaliza e Carrara (2015; 2016) confirma, percebe-se que não cessou o confessar do sexo $e$ o que há de novo é uma reelaboração no modo de constituir subjetividades. Isso não surgiu como abordagem do sexo menos atada aos aparatos e práticas da ciência, da medicina, da psicologia e pedagogia. Observa-se que a sexualidade de adolescentes ficou restrita ao alcance desses discursos e práticas científicas, tidas como palavras finais que a sociedade aceita, divulga e valoriza. Do mesmo modo, no campo da adolescência masculina, a ação tem possibilitado prejuízo na formação. Trata-se das técnicas da negação, da recusa e de tudo que habitualmente é rotulado como repressão. Como já afirmado, são efeitos da vontade de saber e existem, sobretudo, na produção e na circulação de discursos instituídos de saber-poder.

Com a intenção de clarificar a questão, Foucault (2007) e Carrara (2015) afirmam que o poder que produz verdade não se limita a reprimir e ou esconder-se em ideologias. Ao lado dos procedimentos de produção, dos sistemas de signos e de técnicas que colocam condutas dominadoras, há técnicas de si. Nesse sentido, vale ressaltar que

Talvez não estejamos falando mais nem do mesmo "sexo", nem do mesmo "direito", e os efeitos biopolíticos se façam sentir agora de modos mais sutis $e$ indiretos. As atuais preocupações em relação ao sexo não consentido ou em relação ao preconceito e à discriminação homofóbica, por exemplo, têm desenhado vastas categorias de "vulneráveis" (Carrara, 2015:335-336).

Por consequência disso, percebe-se que o adolescente, por si mesmo, exerce certas operações sobre seu corpo, sua alma, seus pensamentos, suas condutas, para produzir nele, transformações e modificações. São temáticas visíveis nos discursos em diferentes espaços, instituições e pessoas ligadas aos sistemas citados. Nesse sentido, refletir sobre a escola nos possibilita pensar que ela é o espaço que referenciará ainda melhor sequência dessa discussão. 


\section{Heteronormatividade masculina adolescente: entre a subjetivação e a violência}

O termo heteronormatividade é usado para exploração $e$ crítica de normas tradicionais de sexo, identidade de gênero, papel social de gênero e sexualidade e implicações sociais de tais instituições. É também descritivo de um sistema dicotômico de categorização que vincula comportamento social e autoidentidade com o tipo de genitália de cada um. Essas demandas reforçam conceituações de que existem fundamentos estritamente definidos de virilidade e feminilidade e comportamentos esperados tanto para mulheres quanto para homens. $\mathrm{Na}$ atualidade, heteronormatividade seria o conjunto de instituições e estruturas de compreensão e orientação prática que, na heterossexualidade, mantém hegemonia por meio de subalternização de outras sexualidades, impondo seu modelo. Para melhor entendimento, carecem de melhor conceituação do que se entende como gênero.

Para Scott (1995), enquanto discurso, o gênero concerne à categoria socialmente imposta sobre um corpo sexuado, mas que, devido à proliferação de estudos sobre sexo e sexualidade, tornouse vocábulo particularmente útil, por oferecer meios de diferenciar práticas de papéis sexuais atribuídos a cada um/a. Weeks (1986) fortalece esse conceito afirmando que

O gênero (a condição social pela qual somos identificados como homem ou como mulher) e a sexualidade, (a forma cultural pela qual vivemos nossos desejos e prazeres corporais) tornaram-se duas coisas inexplicavelmente vinculadas. O resultado disso é que o ato de cruzar a fronteira do comportamento masculino ou feminino apropriado (isto é, aquilo que é culturalmente definido como apropriado) parece algumas vezes, a suprema transgressão (Weeks, 1986:45).

Nessa mesma linha de entendimento, vale considerar que 
Se a diferenciação do gênero decorre do tabu do incesto $e$ do tabu anterior da homossexualidade, então, 'tornar-se' gênero é um laborioso processo de tornar-se naturalizado, processo que requer uma diferenciação de prazeres e de partes corporais, com base no significado com características de gênero. Diz-se que os prazeres residem no pênis, na vagina e nos seios, ou que emanam deles, mas tais descrições correspondem a um corpo que já foi construído ou naturalizado como portador de traços específicos de gênero. Em outras palavras, algumas partes do corpo tornam-se focos concebíveis de prazer precisamente porque correspondem a um ideal normativo de um corpo já portador de um gênero específico. [...] A questão de saber que prazeres viverão e que outros morrerão está frequentemente ligada a qual deles serve às práticas legitimadoras de formação da identidade que ocorrem na matriz das normas de gênero. [...] Os limites do real são produzidos no campo da heterossexualidade naturalizada dos corpos, em que os fatos físicos servem como causas e os desejos refletem os efeitos inexoráveis dessa fisicalidade (Butler, 2003:107-108).

No que tange ao gênero masculino, quer seja no espaço familiar ou escolar, mesmo havendo os discursos heteronormativos vigentes, evidencia-se que cada sujeito está diante de diferentes caminhos para percorrer $e$ inserir-se no decorrer da vida. E encontra no percurso sexualidades e gêneros pré-determinados, podendo, assim, vivenciar e experimentar caminhos diversos.

Portanto, ao pensar na escola como local de experiências fora do espaço doméstico, é possível percebê-la um campo de possibilidades, construção, legitimação e ambientes onde adolescentes do sexo masculino encontram elementos que reforçam ou desconstroem o discurso hegemônico sobre o que é ser homem. Nesse sentido, uma vez construídas e reconstruídas historicamente, masculinidades não podem ser tomadas por realidades imutáveis e objetivas. $\mathrm{O}$ fragmento que segue sinaliza tal questão, 
Minha casa nunca teve uma televisão porque a Igreja da minha família não "permitia" e meus pais sempre seguiram muitíssimo à risca. Então, não vivi onde se falava muito de futebol. Meu pai não jogava. Quando entrei no colégio começaram as cobranças, "se você é macho, tem que saber jogar futebol". Não tive influência em casa, isso tem relação com o não gostar. Achava meio sem sentido, preferia ficar quieto no meu canto, jogando dama ou torrinha na educação física. Também não cresci falando de mulher, do jeito vulgar que muitos falam. Meus pais nunca aceitaram esse tipo de conversa e cresci convivendo só com adultos (Sujeito 10).

$\mathrm{O}$ recorte de fala coaduna com os conceitos de Connell (1995) de que o homem é uma espécie de artefato. Isso mostra o complexo processo que o adolescente masculino enfrenta em sua construção enquanto sujeito, mediante o conceito hegemônico de masculinidade estabelecido. Todavia, a ampliação dos estudos de masculinidade tem permitido outras considerações. Assim, depreende-se que,
A masculinidade hegemônica se distinguiu de outras masculinidades, especialmente das masculinidades subordinadas. A masculinidade hegemônica não se assumiu normal num sentido estatístico; apenas uma minoria dos homens talvez a adote. Mas certamente ela é normativa. Ela incorpora a forma mais honrada de ser um homem, ela exige que todos os outros homens se posicionem em relação a ela e legitima ideologicamente a subordinação global das mulheres aos homens (Connell; Messerschmidt, 2013:245).

Resgatando o comentário anterior, é possível identificar que tais processos de ajuste têm desencadeado inquietação, incômodo e desequilíbrio e o recorte seguinte amplia essa percepção. 
Não sabia jogar bola e lógico que já fui chamado de "viadinho" por conta disso; tirava notas altas e isso ajudava na zuação. Um dia, numa viagem, meus amigos levaram uma playboy escondida no ônibus me mostraram e eu pensei "meu! Como assim? Isso é super errado! A gente não devia estar olhando isso!". Riram e fizeram piadinha, mas devido à minha reação. E aí ouvi: "ui, que moleque gay!" A verdade é que a gente tenta se enquadrar. Ninguém quer viver sentindo-se como se fosse um peixe fora d'água. Aí tentamos aderir "aos padres", o que não é uma tarefa muito fácil (Sujeito 10).

É possível perceber que há conjuntos de práticas socialmente estabelecidas ao masculino e que servem como códigos de enquadramento ao tipo específico de gênero. Ademais, há também condutas esperadas, aprendizados adquiridos $e$ expressos $e$ hábitos cotidianos que servem para classificar $e$ denominar o que está dentro ou fora da norma. Diante das exigências normativas masculinas, somadas ao pensar de Louro (1999), Sedgwick (2007) e os fragmentos aqui inseridos, infere-se que só o despertar de suspeita sobre a não heterossexualidade já gera comportamento homofóbico e desencadeia rejeição nos espaços sociais masculinos. Ainda, na forma como as relações sociais são descritas, notam-se diferenças entre o que se aprende com a família e o exigido em outros espaços, para além da familia.

A cobrança aos comportamentos que fogem à heteronormatividade desencadeia prazer em escapar da fiscalização, da regulação, da punição, do transgredir $e$ escandalizar, sendo um caminho de fuga e resistência de subalternos (Miskolci, 2006). O recorte de fala inserido também possibilita mostrar que a identidade sexual é constructo instável, mutável, volátil e socialmente contraditório e não finalizado, sendo constantemente rearranjada, desestabilizada e desfeita pelas complexidades das experiências vividas na cultura. Objetivamente, assim como Connell (1995) e Connell e Messerschmidt (2013), percebe-se que desvalorizações de certos tipos de masculinidades visam ao fortalecimento do normativo. No fragmento de fala que 
segue, as cobranças são percebidas em atitudes, enunciações $e$ comportamentos.

No sentido de cobrança e pressão elas eram equilibradas entre a escola e meus pais. Em casa doía mais porque pai $e$ mãe é quem a gente confia e se eles duvidam da sexualidade do próprio filho, por não saberem a resposta dificulta até tentar uma comunicação. Meu pai não brigou, só comentou que sabia como era o caminho de ser gay, que não era fácil, que eu ia sofrer muito, mas que o que eu decidisse para ele estava bom e que nada iria mudar entre nós. Foi um alívio mesmo sabendo que eu não era gay (Sujeito 2).

Pelo descrito, cobranças por ajuste e adequação em ambientes de convívio social, extrafamiliar, geram desconforto $e$ enfrentamentos. Entretanto, as exigências e expectativas na família podem ser responsáveis por desajustes e desequilibrios ainda maiores. Os comentários sinalizam que o tornar-se homem é não ser gay, que homossexualidade cumpre papel de ameaça ao masculino hegemônico e há compromisso de dizer não aos posicionamentos que negam a heterossexualidade. Também, sinalizam a possibilidade de repensar as práticas sexuais como boas e más; masculinidades normais e anormais e mais ou menos masculinas; sinalizam com a possibilidade de romper com $\mathrm{o}$ pensar do sexo como vetor de segregação.

Por conseguinte, a sexualidade interdita e regulamentada pela moral religiosa, que aos poucos passou ao domínio da ciência, persiste e dita regras, como Foucault (2007) sinaliza e Carrara (2015) confirma. Há demarcações de lugares influenciando atitudes e práticas específicas no exercício de ser masculino, mesmo diante de situações em que os corpos funcionam de forma diferente do estabelecido pelo campo biológico. Assim - concordamos com Connell (1995) e Connell e Messerschmidt (2013), a masculinidade é uma construção de cada sujeito e, proporcional ao modo como ocorre, serve para 
aceitação ou exclusão. Esclarecendo sobre a masculinidade e as questões de hegemonia, o termo

[...] foi originalmente formulado com uma forte consciência de argumentos psicanalíticos acerca do caráter multifacetado e contraditório da personalidade, da contestação cotidiana como parte da vida social e da mescla de estratégias necessárias a qualquer tentativa de sustentar a hegemonia (Connell; Messerschmidt, 2013:259).

Portanto, é consideravelmente irônico que o conceito seja criticado por simplificar demais o sujeito. Nesse campo, vale ressaltar que a definição de masculinidade hegemônica não equivale a um modelo de reprodução social, pois é preciso reconhecer as lutas sociais nas quais masculinidades subordinadas influenciam formas dominantes. Nesse raciocínio, Parker (1997) reforça que a cultura de dominação do masculino em relação ao feminino ou às outras masculinidades na América Latina é bem marcante, sendo contexto em que os traços de feminilização identificadas no sujeito masculino coloca-o na condição de demérito dentro da hierarquia masculina. O comentário a seguir mostra tal concepção,

Vejo que o meu ponto fraco era ter um jeitinho afeminado, não muito, mas tinha. Daí, quando alguém falava disso, eu ficava muito maus. Eu acho que eu fui uma criança muito forte. Pensa uma criança lidando com esse tipo de coisa, isso é muito difícil! Parecia que tudo que eu fazia de bom ainda tinha esse "defeito" escondido. Isso foi tão ruim que houve momentos que eu pensei em me matar. Tipo, eu pensava em beber veneno (Sujeito 11).

Observar o recorte "parecia que tudo que eu fazia de bom ainda tinha esse defeito escondido" demonstra a marca do que é tido como anormal, defeituoso e desestabilizador do sujeito em construção. Ainda, viabiliza que este sujeito veja sua subjetivação como cheia de falhas ou defeituosa, fortalecendo o conceito de 
que ser reconhecido fora da norma ou não alcançar a masculinidade heteronormativa, pode ser fator sinalizador da intenção $e$ de possibilidades de suicídio ${ }^{5}$ entre adolescentes masculinos de idades entre 14 e 24 anos. A questão aparece em estudos como OMS (2006; 2014), Junqueira (2009), O'Conor (1995), Remafedi (1991; 1995), Gibson (1989) e Garofalo et al. (1998), dentre outros. Também, Arenales et al. (2005), ZwahrCastro (2005), Russell e Joyner (2001), Souza et al. (2002), O'conor (1995), e Russell e Joyner (2001), e fornecem subsidio para entendimentos da instalação da violência, consequência do não ajuste à norma $e$ do não encontro de rotas de fuga possíveis. $\mathrm{O}$ comentário a seguir reforça o que está sendo discutido.

Por conta de cobranças em relação ao meu jeito de ser eu admito que pensei muito em me matar, mas sabia que isso iria piorar, que minha mãe não resistiria. Esse sentimento surgiu quando contei para ela que tinha dúvidas sobre minha sexualidade e durou até uns meses depois. $\mathrm{O}$ sentimento era tão ruim que pensava em pular da ponte ou de um viaduto, de injetar ar nas veias, tomar veneno ou cortar o pescoço. Acho que se minha mãe tivesse me rejeitado no momento em que conversei com ela ou nos dias seguintes, talvez eu tivesse feito isso ou fugido de casa (Sujeito 7).

Mesmo não sendo o foco central desta discussão, ocorrências de suicídio de homens de idade entre 14 e 24 anos têm sido alvo de investigações por diferentes pesquisadores no

\footnotetext{
5 No que diz respeito ao suicídio entre pessoas do sexo masculino, no mundo, entre 1950 e 1980 as taxas triplicaram; de 19 a 54\% dos jovens americanos já pensaram em suicídio, sendo prática mais bem sucedida entre homens de 14 a 24 anos. Esse é o terceiro maior motivo de morte no país em tal faixa etária e, no Brasil, de 26 a $30 \%$ dos casos ocorrem entre pessoas de até 24 anos. Nas regióes metropolitanas brasileiras, o suicídio é a sexta causa de óbitos entre pessoas do sexo masculino na faixa etária citada. Também, essa taxa entre adolescentes é alta $e$ as identidades sexuais estão ligadas a um terço de todo suicídio entre adolescentes no mundo (Zwahr-Castro, 2005) e (Russell; Joyner 2001) .
} 
Brasil e no mundo. Russell e Joyner (2001) e Tamam et al. (2005) demonstram, em seus levantamentos, tanto o agravamento quanto ligações dos suicídios com difíceis ajustes no campo do gênero e da sexualidade masculina. Nos fragmentos aqui inseridos, percebe-se que comportamento homofóbico desencadeia rejeição entre grupos sociais masculinos, além de contribuir para desequilibrios e desajustes entre eles. Nesse sentido, o recorte seguinte ratifica essa perspectiva,

Há um confronto do que sinto e do que meus pais acreditam baseados na bíblia. Tenho rancor na verdade de ideias que considero erradas, afinal todos somos livres para acreditar no que quisermos. Isso tudo foi bem perturbador, me senti muito excluído e de certa forma pensei em suicídio por conta disso. O sentimento é de que eu era um doente, $e$, aliás, até penso nessa possibilidade por isso veio esse sentimento de querer morrer $e$ o que me fez pensar nisso foi o receio daquilo que eu poderia vir a ser (Sujeito 5).

Perante tais constatações, é importante salientar que o foco deste trabalho é a qualidade de vida de adolescentes do sexo masculino. Nesse caminho, desafiamo-nos a construir uma discussão com a finalidade de contribuir para convivências amenas dos processos de objetivação e subjetivação aos quais cada um é submetido e se submete e, ainda, a valorização do respeito e da tolerância. No entanto, nas últimas décadas do século XX, percebe-se a emersão de um fantasma, descrito em relatórios periódicos da OMS (1965; 1975; 2000; 2001; 2006; 2014).

Assim, é possível fazer as seguintes indagações: o medo do fracasso em relação à heteronormatividade estaria contribuindo para suicídios entre adolescentes? Os suicídios decorrentes do fracasso pessoal, questão sinalizada pelos próprios suicidas, teriam sido no século XX e vêm sendo nesse início de século XXI uma nova armadilha do discurso hegemônico? $\mathrm{O}$ fragmento que segue pode auxiliar ou ampliar o questionamento aqui suscitado. 
Quando acordei no hospital, senti um vazio muito grande, me senti sozinho como nunca, aí pensei que precisava ter morrido mesmo. Me senti desvalorizado, como se não tivesse importância alguma no mundo. Mil coisas me passavam, de tristeza, de desespero e de angústia, vontade de não ter nascido. Pensava no desgosto de minha família. Veio nos dias que seguiram uma profunda depressão que dormia o tempo todo para não enfrentar nada. Muito tempo depois, foquei nas coisas boas que eu teria perdido se eu tivesse realmente me matado. Logo em seguida, eu contei para os meus pais que era gay e o motivo de minha tentativa de morte (Sujeito 10).

Os comentários "senti um vazio", "sozinho como nunca", "desvalorizado", "tristeza", "desespero", "angústia", "vontade de não ter nascido" e "desgosto de minha família" refletem o pensado sobre uma tentativa de suicídio, os motivos e a consequência disso. Mediante o recorte, há de se retomar à discussão sobre mecanismos disciplinares e sua forma enraizada por todos os espaços sociais. Há de se ponderar também o considerável sufocamento exercido por ele aos que não se ajustam às normas estabelecidas. Tal raciocínio possibilita saber que as resistências nesse campo, mesmo considerando que o desejo é fugaz e capaz de propiciar rotas de fuga, não têm possibilitado, em alguns casos, fugir, desencadeando suicídio de adolescentes fora da norma heterossexual.

Nisso, percebe-se que a construção do masculino, como experiência, desencadeia sofrimento, gera desequilíbrio, inquietação e reforça hipóteses de que dificuldades enfrentadas podem contribuir na elevação da taxa de suicídio entre os adolescentes. A identificação de afirmativas como "quando contei a minha mãe que tinha dúvidas sobre minha sexualidade, o medo de ser rejeitado me fez pensar em pular de um viaduto", "me matar era um pensar decorrente do preconceito que sentia vindo de toda a família, amigos a sociedade no geral" $e$, ainda, a tentativa de suicídio de um dos participantes, meses após ser entrevistado para o trabalho aqui apresentado, reforçam essa 
hipótese. Pressupõem que objetivação e subjetivação, questões de sexualidade e gênero entre adolescentes, ocorrem através de aprendizagens $e$ práticas, investidas por instâncias sociais $e$ culturais inesgotáveis, explícitas ou dissimuladas e que o não ajuste à norma causa violência.

Para além do entendimento dado sobre suicídios entre adolescentes, é Foucault (2007; 2011b) quem explica que todos têm o direito de vida e morte, tanto que na Grécia orientava-se para o exercício de pensar no morrer como momento comum $e$ coisas quaisquer. Seria por meio desse olhar que deviam ocuparse, considerando o morrer moralmente valioso e belo. Portanto, pensando na vida ao invés da morte, o empreito não deveria ser o de fortalecimento e valorização da singularidade de cada um? Como contribuir para que discursos sejam de fato fortalecedores $e$ de valorização para com o viver? O fragmento de fala ${ }^{6}$ a seguir mostra possibilidades nesse sentido.

Não importo com o que digam, sou mãe, ele nasceu de dentro de mim. Como não amá-lo? Quero é que ele seja feliz. Ele é uma das três coisas mais importantes da minha vida, prefiro morrer que perdê-lo. Fiquei triste porque naquele dia eu teria evitado se tivesse ligado, difícil pensar que ele falou comigo e com o pai pelo telefone se despedindo. Quando cheguei ao hospital, ele levantou, chorou, e eu sem saber de nada disse, filho levanta daí, vamos pra casa. Semanas depois quando ele falou de ser gay, na hora eu pensei na tentativa de suicídio. Ele não nos disse na hora, nem no mesmo dia, mas eu pensei: "naquele dia ele tentou se matar" (Sujeito 14).

${ }^{6}$ Os recortes de fala do sujeito 14 e do sujeito 15 são procedentes da entrevista de um pai e uma mãe, cujo filho foi integrante do grupo de 17 sujeitos entrevistados e, que alguns meses depois de encerradas as entrevistas, tentou suicídio. Após sua recuperação física, nos meses que se seguiram, buscou-se realizar novas entrevistas e os pais do adolescente também aceitaram disponibilizar seus depoimentos sobre a experiência vivencidada. 
O comentário é contrastante se comparado aos enfrentamentos vivenciado por pais, filhos e responsáveis, diante de identidades sexuais fora da norma. Contudo, apesar de não ser referência de cotidiano, há possível entendimento de que o assujeitamento de pais aos modos de subjetividades dos filhos propicia uma convivência menos conflituosa e o recorte a seguir vem acrescer sobre a questão.

De repente eu me peguei ali pensando que meu filho tava surtando com problemas, questionando se sou capaz de amá-lo como ele é. Pensei, preciso que ele saiba que o amo. Aí o abracei e disse papai te ama, não vai mudar nada. Ali eu beije abracei e lutei para que ele ficasse calmo de novo (Sujeito 15).

Foucault (2011b), ao descrever ensinamentos gregos, afirma que essa é a ação: colocar-se na melhor situação possível e morrer em cada momento. Assim, para além dos fragmentos, que seja pensado na vida, no morrer para viver, o deixar-se morrer naquilo que mata o outro ou tira o prazer de viver, para que, eu e o outro vivamos o pós-morte. Poderíamos dizer que tal conduta seria viver como uma obra de arte. Seria matar o que impede liberdades, falamos de liberdade ao se respeitar subjetividades e o sentido grego dado a meletê thanatou. $\mathrm{O}$ autor orienta que o termo não está ligado ao pensar no futuro e sim a valorizar ações do presente.

A meditação sobre a morte é, em sua forma geral, totalmente isomorfa à presunção, à premeditação dos males [...] simplesmente por (essa primeira razão): a morte não é apenas um acontecimento possível, é um acontecimento necessário. Não é apenas um acontecimento com alguma gravidade: tem para o homem a gravidade absoluta. $\mathrm{E}$ enfim, a morte pode ocorrer, bem sabemos, a qualquer momento (Foucault, 2011b:429). 
Nesse raciocínio, o século XXI tem se mostrado volátil. Nunca relações sociais e modos de vida foram tão alterados, exigindo novas adequações e ajustes. Sendo assim, por que não lutar para estabelecer uma nova estética de existência para adolescentes? Sobre diferenças e o normativo esperado, Scott (1995) traça que diferenças não são aspectos univocamente estabelecidos e reconhecíveis, sendo melhor evitar armadilhas de tomar dadas diferenças e tornar visíveis processos sociais que as criam.

Para o autor, a diferença é resultado da designação do outro $e$ que distingue categorias de pessoas a partir da norma presumida. Desse maneira, precisamos interferir nos processos de segregação, romper com os discursos acadêmicos e fazer insurreições daquilo que adolescentes discursam sobre quem são. É provável que isso seja possivel mediante o que tais adolescentes acham do que esperam deles e o modo de resolverem isso. Então, romper com conceitos de sexualidade como ímpeto rebelde, estranho por natureza $e$ indócil por necessidade seria um caminho?

Para Foucault (2007), a sexualidade não é elemento rígido e, dotada da maior instrumentalização, ela tem sido utilizada em inúmeras manobras, servindo de apoio $e$ articulação nas mais variadas estratégias. Há também reforço de que sexualidades e questões de gênero são dispositivos históricos e grandes redes de superfícies que estimulam corpos, intensificam prazeres e incitam discursos. Também, o poder não é repressivo, opressivo, sua maior força está na riqueza produtiva gerada entre poder $e$ resistência. Então, há de se perceber que, entre adolescentes, a norma tem se fortalecido por meio de masculinidades tidas como subalternas e gerado assujeitamento. São mecanismos importantes na construção do masculino, embora em algumas circunstâncias, em caso de difícil ajuste, possibilitem a instalação da violência $e$ do consequente risco de suicídio. 


\section{Considerações finais}

Os fragmentos de fala analisados nesta pesquisa subsidiam salientar a necessidade de posicionamentos críticos frente à produção das identidades sexuais e de gênero. Elas aprisionam os sujeitos nos dispositivos de assujeitamento que os produziram e, para além do campo da resistência, podem levá-los a um terceiro campo - o da violência. Notou-se que um dos campos no qual a violência está estabelecida é o suicídio - uma prática frequentemente pensada ou executada entre aqueles não conseguem se ajustar à norma ou resistir a ela.

Portanto, referenciado nos fragmentos de fala, é estratégico pensar no contexto das lutas políticas de minorias. Nesse sentido, é pertinente, em nível tático, não recorrer à obrigatoriedade de se dizer "sou homossexual". Como uma estratégia mais ampla, uma opção seria o questionamento dos rótulos de identidade. Ao invés de confirmá-la, recusar a injunção de identificação mediante diferentes formas de sexualidade. Seria a recusa do satisfazer a obrigatoriedade de identificação, referenciada apenas em uma sexualidade padrão.

Sendo assim, a expectativa, conforme Britzman (1996), é que questões de desejos, de amor, de afetividade e de identidade, continuem surpreendendo a cada um; que embates sociais entre poder e resistência possibilitem a criação de formas de sociabilidade, de política e de identificação que desvinculem o eu dos discursos dominantes da biologia, da natureza, da normalidade e promovam vida para que a morte não seja alternativa.

\section{Referências bibliográficas}

ARAÚJO, Ines Lacerda. Foucault e a crítica do sujeito. Curitiba, Editora UFPR, 2000.

ARENAleS, Luis; ArenAles, Nelma Hollanda Boti; CruZ, José. Autópsia psicológica em adolescente suicida: Relato de caso. Suicídio conhecer 
[http://www.polbr.med.br/ano02/artigo0502_b.php - acesso em 09 mar. 2018].

ARIÈs, Philippe. História Social da Criança e da Família. Rio de Janeiro, Zahar editores, 1981.

BADINTER, Elisabeth. XY: Sobre a identidade masculina. Rio de Janeiro, Nova Fronteira, 1999.

ButTLER, J. Problemas de gênero: Feminismo e subversão da identidade. Rio de Janeiro, Civilização Brasileira, 2003.

BRITZMAN, Débora. O que é essa coisa chamada amor: Identidade homossexual, educação e currículo. Educação e Realidade, vol. 21, 1996, pp.71-96.

CARRARA, Sérgio. Moralidades, racionalidades e políticas sexuais no Brasil contemporâneo. Mana, vol. 21, $\mathrm{n}^{\circ}$ 2, Rio de Janeiro, ago. 2015, pp.323-345.

A antropologia e o processo de cidadanização da homossexualidade no Brasil. cadernos pagu, Campinas-SP, Núcleo de Estudos de Gênero-Pagu/Unicamp, 2016.

CASTRO, Lucia Rabello. Infância e adolescência na cultura do consumo. Rio de Janeiro, NAU, 1999.

. Subjetividade e cidadania: um estudo com crianças e jovens em três cidades brasileiras. Rio de Janeiro, 7 Letras, 2001.

CÉSAR, Maria Rita Assis. A invenção da "adolescência" no discurso psicopedagógico. Dissertação (Mestrado em Educação) - Faculdade de Educação, Universidade Estadual de Campinas, Campinas, 1998.

Colmbra, Candido Celso; Bocco, Fernanda; NAscimento, Maria Livia. Subvertendo o conceito de adolescência. Arquivos Brasileiros de Psicologia, Rio de Janeiro, vol. 57, n 1, 2005, pp.02-11.

CONNEll, Robert Willian. Políticas da masculinidade. Educação \& Realidade, vol. 20, n² 2, 1995, pp.02-22.

; Messerschmidt, James W. Masculinidade hegemônica: repensando o conceito. Revista Estudos Feministas 21(1), Florianópolis, janeiro-abril 2013, pp.241-282 
FERNANDES, Cleudemar. Alves. Discurso e sujeito em Michel Foucault. São Paulo, Intermeios, 2012.

FISCHER, Rosa Maria Bueno. Foucault e a análise de discurso em educação. Cadernos de pesquisa, n 114, Porto Alegre, 2001, pp.197223.

Foucault, Michel. Microfísica do poder. Rio de Janeiro, Edições Graal, 1979.

O sujeito e o poder. In: DREYFUS, H.; RABINOW, P. (org.). Michel Foucault: uma trajetória filosófica - para além do estruturalismo e da hermenêutica. Rio de Janeiro, Forense Universitária, 1995, pp.231249. 2003.

. A verdade e as formas jurídicas. Rio de Janeiro, NAU Editora,

- Ditos e Escritos. volume IV. Rio de Janeiro, Forense Universitária, 2004.

. História da sexualidade volume I: a vontade de saber. Rio de Janeiro, Graal. 2007. 2008.

A arqueologia do saber. Rio de Janeiro, Forense Universitária.

. História da sexualidade volume II: o uso dos prazeres. Rio de Janeiro, Graal, 2010.

. A ordem do discurso. São Paulo, Loyola, 2011a.

. A hermenêutica do sujeito. São Paulo, Martins e Fontes, 2011b.

FREITAS, Henrique et al. Pesquisa via internet: Características, processo e interface. Revista Eletrônica GIANTI, 2004. Disponível em: [http://www.ufrgs.br/gianti/files/artigos/2004/2004_140_rev_eGIANTI. pdf acesso em 09 mar. 2018].

FRY, Peter. Para inglês ver: identidade e política na cultura brasileira. Rio de Janeiro, J. Zahar, 1982.

ROBERT, Garofalo et al. The association between health risk behaviors and sexual orientation among a school-based sample of adolescents. Pediatrics, vol. 101, 1998, pp.895-902. 
GiBSON, Paul. Gay male and lesbian youth suicide. In: U.S. Department of Health and Human Services. Report of the Secretary's Task Force on Youth Suicide, Washington U.S.A. Government Printing Office, 1989, pp.110-142.

JOBIM E SouZA, Solange. Ressiginificando a psicologia do desenvolvimento: uma contribuição critica à pesquisa da infância. In: KRAMER, S.; LEITE, M. I. Infância: fios e desafios da pesquisa. Campinas, Papirus, 1998, pp.39-56.

JUNQUEIRA, Rogério Diniz. Homofobia nas escolas: Um problema de todos. In: . Diversidade Sexual na Educação: problematizaçóes sobre a homofobia nas escolas. Brasília, Ministério da Educação, Secretaria de Educação Continuada, Alfabetização e Diversidade, UNESCO, 2009, pp.13-52.

Louro, Guacira Lopes. O corpo educado: Pedagogias da sexualidade. Belo Horizonte, Autentica, 1999.

MANN, Chris; STEWART, Fiona. Internet communication and qualitative research: A handbook for researching online. London, SAGE Publications, 2000.

MARCUSCHI, Luiz. Antônio. Gêneros textuais emergentes no contexto da tecnologia digital. In: MARCUSCHI, L. A.; XAVIER, A. C. S. (orgs.). Hipertexto e Gêneros Digitais. Rio de Janeiro, Lucerna, 2004, pp.1367.

MISKOLCI, Richard. Corpos elétricos: Do assujeitamento à estética da existência. Revista Estudos Feministas, Florianópolis, IEF, 2006, pp.681-693

Novas conexões: Notas teórico-metodológicas para pesquisas sobre o uso de mídias digitais. Cronos. R. Pós-Grad. Ci. Soc. UFRN, vol. 12, n², 2011, pp.09-22.

O'CONOR, Andi. Breaking the silence. Nova Iorque, Routledge, 1995.

OrganizaÇão Mundial da Saúde (OMS). Problemas de la salud de la adolescencia. Informe de un comité de expertos de la - Informe técnico n ${ }^{\circ}$ 308, Genebra, 1965, pp.07-56.

. El embarazo y el aborto em la adolescencia. Genebra, 1975. 
. Prevenção do suicídio: Manual para Professores e educadores. Genebra, 2000.

. Relatório sobre a saúde mental no mundo. Genebra, 2001. 2006.

. Prevenção do Suicídio: um recurso para conselheiros. Genebra, . Preventing suicide: a global imperative. Luxembourg, 2014.

Ozella, Sérgio. Adolescência: uma perspectiva crítica. In: Conselho Federal de Psicologia. Adolescência e psicologia: concepçóes, práticas e reflexóes críticas. Rio de Janeiro, 2002, pp.16-24.

PARKER, Richard. Reflexões sobre a sexualidade na sociedade LatinoAmericana: Implicações para intervenções em face do HIV/AIDS. Physis. 1997, pp.99-108.

PERALVA, Angelina. Escola e violência nas periferias urbanas francesas. Contemporaneidade e educação, Rio de Janeiro, ano 2, n 2, 1997, pp.07-25.

REMAFEDI, Gary. Risk factors for attempted suicide in gay and bisexual youth. Pediatrics vol. 87, n6, U.S.A., 1991, pp.869-875.

. Studies of gay and lesbian youth suicide. Boston, Alyson Publications, 1995.

RUBIN, Gayle. The traffic in women: Notes on the 'political economy' of sex. In: REITER, R. Toward an Anthropology of Women. New York, Monthly Review Press, 1975, pp.33-65.

RUSSELL, Stephen T.; JOYNER, Kara. Adolescent sexual orientation and suicide risk: Evidence from a national study. American Journal of Public Health, vol. 91, nº 8, 2001, pp.1276-2001.

SANTOS, Welson Barbosa. Adolescência heteronormativa masculina: entre a construção obrigatória e a desconstrução necessária. Tese (Doutorado em Educação) - Programa de Pós-Graduaçao em Educaçao, Universidade Federal de São Carlos, São Carlos, 2015.

SANTOS, Welson Barbosa; DINIS, Nilson Fernandes. Adolescência heteronormativa masculina: entre a construção "obrigatória" $e$ desconstrução necessária. Revista Opsis, vol. 13, n 2, 2013, pp.129149. 
SCOTT, Juan. W. Gênero: uma categoria útil de análise histórica. Educação \& Realidade. Porto Alegre, vol. 20, n 2, 1995, pp.71-99.

SEDGWICK, Eve Kosofsky. A epistemologia do armário. cadernos pagu (28), Campinas-SP, Núcleo de Estudos de Gênero-Pagu/Unicamp, 2007, pp.19-54.

SouZA, Edinilsa Ramos; MINAYO, Maria Cecília Souza; MALAQUIAS, Juaci Vitória. Suicídio de jovens nas principais capitais do Brasil. Caderno de Saúde Pública, Ribeirão Preto, vol.18, n 3, 2002, pp.673-683.

TAMAM, Lut; ÖZPOYRAZ, Nurgül; Diler, Rasim S. Homosexuality and suicide: $\quad A \quad$ case report. 2005 [http://ams.cu.edu.tr/January2001Vol10No1/suicide.htm - acesso em 25 jul 2014].

WARNER, Michael. Fear of a queer planet: Queer Politics and Social Theory. London, University of Minnesota Press, 1991.

WeEKS, J. Sexuality. New York, Routdledge, 1986.

ZWAHR-CASTRO, Jennifer. O suicídio entre adolescentes americanos. Revista espaço acadêmico, ano 04, n 44, 2005, pp.10-15. 